EMBRYARIDDLE
Aeronautical University

SCHOLARLY COMMONS
International Journal of Aviation, Aeronautics, and Aerospace

\title{
Folding Methodology for Flexible Aircraft Interiors
}

Aditya Venkatesh

Ryerson University, Toronto, Canada, avenkatesh@ryerson.ca

Fengfeng (Jeff) Xi

Ryerson University, Toronto, Canada, fengxi@ryerson.ca

Joon Chung

Ryerson University, Toronto, Canada, j3chung@ryerson.ca

Follow this and additional works at: https://commons.erau.edu/ijaaa

Part of the Other Aerospace Engineering Commons

\section{Scholarly Commons Citation}

Venkatesh, A., Xi, F., \& Chung, J. (2021). Folding Methodology for Flexible Aircraft Interiors. International Journal of Aviation, Aeronautics, and Aerospace, 8(1). https://doi.org/10.15394/ijaaa.2021.1518

This Article is brought to you for free and open access by the Journals at Scholarly Commons. It has been accepted for inclusion in International Journal of Aviation, Aeronautics, and Aerospace by an authorized administrator of Scholarly Commons. For more information, please contact commons@erau.edu. 
According to the International Civil Aviation Organization (ICAO), there were 4.233 billion passengers transported in 2018 (ICAO, 2019). The increased number of passengers signifies the importance of positive travel experience. Onboard experience has become an important aspect for the aviation industry as commercial, and business aircraft operation heavily depends on passengers' satisfaction. Recognizing the impact of passengers' experience, growing research into aircraft cabin interiors is expected to be a major driving factor in the global economy of the aerospace industry ("Aircraft Cabin," 2019).

On-board experience is subjective and has driven various studies to understand the necessities of passengers. A study by Bouwens et al. showed that passengers are most comfortable right after take-off and arriving at the destination, and least comfortable during the cruise phase of the journey (Bouwens, 2017). It is not ideal if the passengers are least comfortable while the aircraft is cruising, as it is usually the longest phase of air travel. Hiemstra-van Mastrigt reported that interaction with other passengers or even walking around the aircraft had a positive impact on passengers' on-board experience (Hiemstra-van Mastrigt, 2015). According to Vink et al. (2004), careful attention to aircraft interior design and the passenger flight experience can enhance the overall on-board experience for passengers. Unfortunately, aircraft cabins are rigid environments that do not allow passengers with the flexibility of pursuing activities that they desire.

Space-saving multi-functional furniture is a practical solution for aircraft cabin where space is limited for passenger activities. This application is already implemented with tray tables, which are stowed away when not in use. Aim Altitude introduced the ULTRAFLEX concept that can transform commercial aircraft interiors into "a multi-functional destination area where passengers may move around, interacting with activities and each other, to alleviate boredom and aid health and well-being" (Ultraflex, 2019). Adient Aerospace's Space For All (SFA) concept, offers a deployable multi-functional flat surface from the lower bulkhead wall to front row passengers (UKi Media \& Events, 2020). Vink et al. developed a collapsible bed, that transforms into a 3-seat bench for their Flying V aircraft (Vink, 2020). These concepts aim at maximizing the functionality of the limited space that is available within an aircraft cabin.

While there are various space-saving techniques such as stacking, implosion, and bundling; folding is the most common and allows furniture pieces to be stowed into a more compact form or modified into a new form (Mollerup, 2001). Origami is a Japanese paper folding technique that has inspired numerous applications in medicine, architecture, space, and other engineering systems (Johnson et al., 2017; Lang, 2009; Reis, 2015; Turner et al., 2015). This popular folding technique can be directly applied to fold furniture pieces.

One such extension called foldabilization is an optimized furniture folding process developed by Li et al. (2015, p. 1) with which, "Given a 3D object O 
representing a piece of furniture, our goal is to apply a minimum amount of modification to $\mathrm{O}$ to allow its parts to be folded flatly onto themselves or each other." This technique systematically deconstructs a piece of furniture to allow its folding in a specific direction along the added folding lines. The foldabilization process can be translated to consider furniture pieces found within an aircraft.

This paper introduces a folding methodology that aims at increasing the functionality of an aircraft cabin. This is achieved by minimizing the furniture piece's surface area to maximize the cabin surface area for usage called Open-onDemand, and shifting the geometry of an aircraft furniture piece into a new configuration while maintaining its original material volume called Reconfiguration. The implementation of the Open-on-Demand concept will allow existing on-board furniture pieces to be stowed away, which creates a multifunctional space for the passengers to pursue any on-board activity of their liking. The reconfiguration concept will allow passengers to change the form of existing furniture into a new form, thereby increasing the functionality of the original furniture piece. These applications will give passengers flexibility in an otherwise rigid cabin environment.

\section{Problem Statement}

If a passenger desires a different cabin environment, aircraft needs to undergo an expensive and time-consuming retrofitting process. While being retrofitted, the aircraft needs to be grounded and recertified before its re-entry into service.

This paper establishes a furniture folding methodology that can be applied to aircraft cabin interiors to enhance on-board experience without grounding the aircraft. Open-on-Demand and Reconfiguration are proposed as two cabin interior applications based on the furniture folding methodology. These concepts were developed while considering the relationship and impact of improved cabin interiors on passengers' comfort onboard the aircraft. This study considers business jets as the case study aircraft for the application of the furniture folding concepts. Business jets are designed for flexible uses, which make them an ideal testbed to validate and iterate new cabin interior concepts.

\section{Folding Methodology}

The first step in establishing the folding methodology is defining the design space. This includes identifying and characterizing the Function Requirements (FR), Design Parameters (DP), Design Matrix (DM), and Modules. Suh (1998) defines Function Requirements (FR) and Design Parameters (DP) as:

Functional Requirement: a minimum set of independent requirements that completely characterizes the functional needs of the product (or software, organizations, systems, etc.) in the functional domain. By definition, each FR is independent of every other one at the time the FRs are established. 
Design Parameter: design parameters are the key physical (or other equivalent terms in the case of software design, etc.) variables in the physical domain that characterize the design satisfying the specified FRs." (Suh, 1998, p. 205)

The FRs and DPs of furniture pieces found within an aircraft cabin can be identified and compiled into individual vectors. The FRs and DPs of the commonly found furniture pieces on business jets are listed in Table 1, while Figure 1 illustrates their zero-thickness frame.

Table 1

Complied FRs and DPs of Common Furniture Pieces in a Business Jet.

\begin{tabular}{|c|c|c|}
\hline Piece & $\begin{array}{l}\text { Function } \\
\text { Requirements }\left(F R_{i}\right)\end{array}$ & Design Parameters $\left(D P_{j}\right)$ \\
\hline Chair & $\begin{array}{l}\text { - } \text { Sit } \\
\text { - } \text { Lean } \\
\text { - Sleep } \\
\text { - } \text { Rest Arm/Head } \\
\text { - } \quad \text { Eat }\end{array}$ & $\begin{array}{ll}\text { - } & \text { Physical Dimension } \\
\text { - } & \text { Recline Angle } \\
\text { - } & \text { Cushion Thickness } \\
\text { - } & \text { Legroom } \\
\text { - } & \text { Armrest Height } \\
\text { - } & \text { Backrest Height } \\
\end{array}$ \\
\hline Sofa & $\begin{array}{ll}\text { - } & \text { Sit } \\
\text { - } & \text { Sleep } \\
\text { - } & \text { Lean } \\
\text { - } & \text { Eat } \\
\text { - } & \text { Watch TV }\end{array}$ & $\begin{array}{ll}\text { - } & \text { Physical Dimension } \\
\text { - } & \text { Recline Angle } \\
\text { - } & \text { Cushion Thickness } \\
\text { - } & \text { Viewing Distance from TV } \\
\text { - } & \text { Backrest Height } \\
\text { - } & \text { Sitting Eye Level Height } \\
\end{array}$ \\
\hline Credenza & $\begin{array}{l}\text { - } \text { Personal Storage } \\
\text { - } \text { TV stand } \\
\text { - } \\
\text { Avionics storage }\end{array}$ & $\begin{array}{ll}\text { - } & \text { Physical Dimension } \\
\text { - } & \text { Storage Space } \\
\text { - } & \text { Number of Compartments } \\
\text { - } & \text { TV Dimension } \\
\end{array}$ \\
\hline Table & $\begin{array}{ll}\text { - } & \text { Workspace } \\
\text { - } & \text { Rest Arm } \\
\text { - } & \text { Dining Space } \\
\end{array}$ & $\begin{array}{ll}\text { - } & \text { Physical Dimension } \\
\text { - } & \text { Knee Height Clearance } \\
\text { - } & \text { Armrest Height } \\
\end{array}$ \\
\hline
\end{tabular}




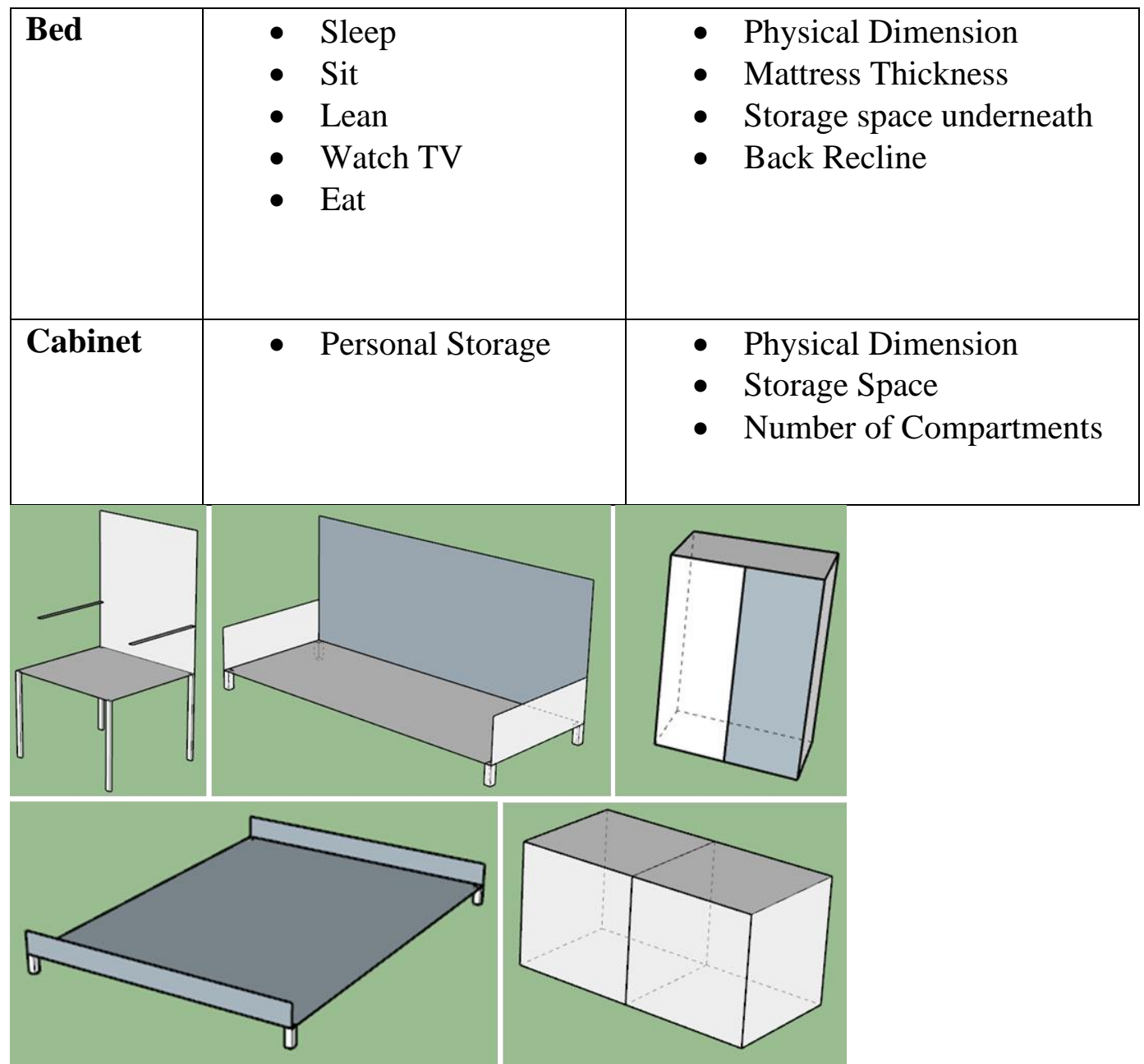

Figure 1. Zero-thickness frame of a seat, sofa, cabinet, credenza, and bed (clockwise).

Breaking down the furniture piece into FRs and DPs helps identify the furniture pieces with dissimilar FRs, so their functionalities can be expanded by applying the furniture folding methodology.

The relationship between FRs and DPs is characterized by a Design Matrix (DM) (Suh, 1995). For the purposes of the furniture folding methodology, the DM is defined as the Folding Design Matrix (FDM), as seen in Equation (1), where $i$ and $j$ indicate the FR and DP elements, respectively.

$$
F R_{i}=\left[\begin{array}{cc}
F D M_{i j} & \cdots \\
\vdots & \ddots
\end{array}\right] \times D P_{j}
$$


The FDM reflects a user's choice to transform a furniture piece from its initial form to the user's desired final form.

A modular breakdown allows a furniture piece's physical geometry to be decomposed into components that can be folded to transform the furniture pieces. A furniture piece's modular composition and layout determines the transformation process it can undergo to be folded into its potential new form. Table 2 shows the modular breakdown of the furniture pieces, on-board business jets, into a combination of panels and columns.

Table 2

Modular breakdown of common business jet furniture pieces

\begin{tabular}{|l|l|l|}
\hline \multirow{2}{*}{ Furniture Piece } & Modules & Columns \\
\cline { 2 - 3 } & Panels & 4 \\
\hline Seat & 2 & 4 \\
\hline Sofa & 4 & 4 \\
\hline Bed & 3 & 0 \\
\hline Standard two door credenza & 8 & 0 \\
\hline Table & 1 & 0 \\
\hline Cabinet & 7 & \\
\hline
\end{tabular}

Based on their modular breakdown, the furniture pieces can be split into two groups, the 'Comfort family' and the 'Function family.' The seat, sofa and bed fall into the 'Comfort family' while the table, credenza, and cabinet fall into the 'Function family.'

The furniture pieces within the two families of furniture can be further classified based on their composition of 'Common modules' and 'Singular modules'. Furniture pieces with Common modules include pieces with overlapping FRs that require no changes to their DPs to satisfy a user's new needs. This means furniture pieces do not need any modifications to their original form to satisfy the desired FRs of the user. Meanwhile, furniture pieces with the Singular modules include pieces that do not have overlapping FRs but can have their DPs modified to satisfy the user's new needs. This means the user's new requirements can be fulfilled by making minimum changes to the Singular modules of the furniture pieces initial form to increase its functionality. Furniture pieces within the same family are more likely to share Common modules when compared to the furniture pieces from the other family.

The change in a Singular modules' geometry can be quantified by studying the two-dimensional change in its aspect ratio between its initial form and final form. "Aspect ratio (AR) is a relative object property that denotes a particular relationship between an object's height and width $(A R=H / W)$ when considered 
within an object-based reference frame" (Davis, 2003). A Singular module's expansion or contraction can be quantified by the 'Folding Module Ratio (FMR)', which is the quotient of the Singular modules' initial and final aspect ratios. This analysis reflects the change in footprint dimensions of module of the furniture piece. As seen in Equation (2), an FMR value greater than one represents contraction, while an FMR value lesser than one represents expansion.

$$
\begin{gathered}
\text { Folding Module Ratio }(F M R)=\frac{\text { Initial Module Aspect Ratio }}{\text { Final Module Aspect Ratio }} \\
\qquad \begin{aligned}
\text { If } F M R & >1 \rightarrow \text { Contraction; } \\
F M R & <1 \rightarrow \text { Expansion; } \\
F M R & =1 \rightarrow \text { No Change }
\end{aligned}
\end{gathered}
$$

The furniture pieces being considered for modification are rigid object in their true forms. Folding lines, joints and locks enable the rigid modules to be modified to different forms. Folding lines allow modules to be folding in specific orientations depending on the type of kinematic joint that is place along said folding line. Sliding joints and rotational joints are the two types of kinematic joints used for the purpose of module modification. These joints can work separately or in tandem to provide the necessary motion along the folding line. Both types of joints are capable of one degree-of-freedom to mitigate any chance of mishaps during the transformation process.

Aircraft regulations require that any item of mass be secured in place and not operated during take-off, landing, and in-flight turbulence (FAA, 1972; TC, 1996). Hence, the furniture pieces can only be undone and transformed while the aircraft is on the ground or during its cruise phase. Push button pin tumbler locks will hold the modules in place and at least two locks will need to be placed along each joint for redundancy.

The furniture pieces can be transformed by following the General Furniture Folding Methodology outlined in Figure 2. The framework allows the user to transform a furniture piece and take advantage of the additional functionality.

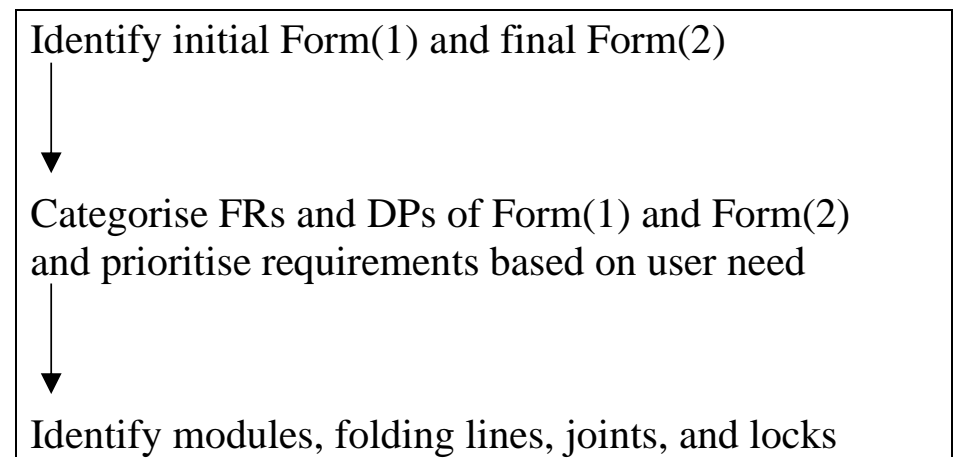




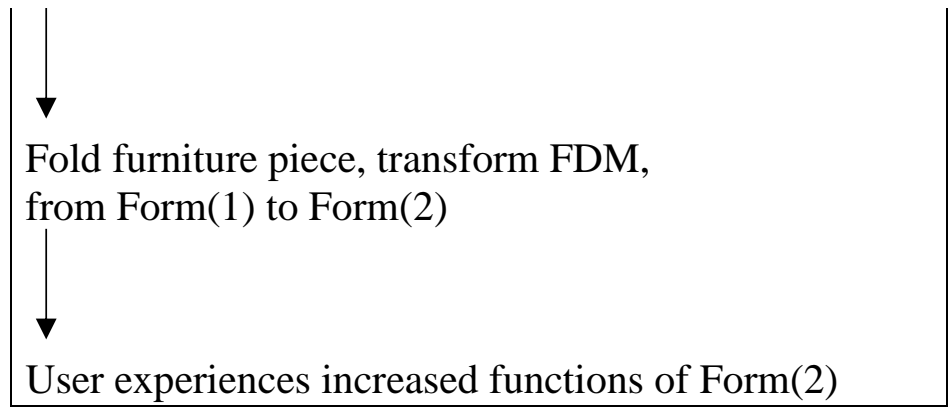

Figure 2. Flowchart outlining the proposed general folding methodology.

The general furniture folding methodology allows a furniture piece to shift its geometry into a new configuration while maintaining its original material volume. This geometric transformation can be quantified using Equation (3).

\section{Form (1) Form (2)}

$$
L_{1} W_{1} H_{1}=x L_{2} y W_{2} z H_{2}
$$

Consider $L_{1}, W_{1}$, and $H_{1}$ to be the respective length, width and height measurements of the initial form of the furniture piece and $L_{2}, W_{2}$, and $H_{2}$ to be the respective length, width and height measurements of the final form of the furniture piece. In equilibrium, the furniture piece's initial volume is equal to its final volume and this is depicted in Equation (3). The variables $x, y$, and $z$ in Equation (3) indicate the directional multipliers of the furniture piece. These directional multipliers act as proportionality constants and signify the expansion or contraction of a dimensional measurement of the furniture piece after the folding process.

Equation (3) can be deconstructed to indicate changes in one, two and/or three dimensions. Table 3 illustrates the different forms of Equation (3) based on the measurement change in the respective dimension. A directional multiplier value less than one indicates an increase in the respective measurement, while a directional multiplier value greater than one indicates a decrease in the respective measurement. In the event there is no change in measurement of the furniture piece in a certain dimension, the respective dimensional multiplier is one. 
Table 3

Dimensional breakdown of Equation (3)

\begin{tabular}{|c|c|}
\hline Dimension(s) & Length \\
\hline One (1-D) & $\begin{array}{c}L_{1}=x L_{2} \\
W_{1}=y W_{2} \\
H_{1}=z H_{2}\end{array}$ \\
\hline Two (2-D) & $\begin{array}{c}L_{1} W_{1}=x y L_{2} W_{2} \\
L_{1} H_{1}=x z L_{2} H_{2} \\
W_{1} H_{1}=y z W_{2} H_{2}\end{array}$ \\
\hline Three (3-D) & $L_{1} W_{1} H_{1}=x y z L_{2} W_{2} H_{2}$ \\
\hline
\end{tabular}

Another technique to signify the transformation of the furniture pieces is to analyze the ratio of its surface area to its volume, depicted in Equation (4).

$$
\text { Surface Area }(S A) \text { : Volume }(V)
$$

The surface area to volume ratio is an ideal metric for the folding methodology as it considers a furniture piece's change in surface geometry while maintaining its material volume. For the purposes of the furniture folding methodology, the surface area to volume ratio is termed 'Total Compactness Ratio (TCR)'. The TCR value is inversely proportional to the compactness of the furniture piece. A larger TCR value for Form(2) when compared to Form(1) signifies a more compact Form(2), and vice versa. The percentage change in the denseness of between the two forms of the furniture piece is characterised by Equation (5).

$$
\left(1-\frac{T C R_{\text {extended }}}{T C R_{\text {folded }}}\right) \times 100
$$

The two mathematical methods mentioned above quantify the transformation of the furniture piece as a whole and as a product of its components. Equation (3) helps measure a furniture piece's change in occupied space while Equation (5) helps measure a furniture piece's percentage change in compactness.

\section{Application to Aircraft Cabins}

Open-on-Demand and Reconfiguration are two design concepts that utilize the general furniture folding methodology. Open-on-Demand will allow passengers to stow away furniture pieces when they are not in use. This opens a multifunctional space that the passenger may use as they desire. This is especially advantageous on long haul journeys as the passengers can utilize the extra space to engage in different activities and alleviate their stress. 
The reconfiguration concept will allow passengers to modify an existing furniture piece into a suitable form of their liking, thereby increasing the furniture piece's functionality. Users can shift the Common and/or Singular modules of the initial form of the furniture piece into a new arrangement of their choice. The final configuration of a furniture piece is dependent on the modular orientation and layout of its initial form. Not all furniture pieces can be reconfigured to the users desired form. This concept can be applied to furniture forms that share Common modules, at it can be used to alter the amount of space occupied by the furniture piece in its true form. This application is a quick, low-cost, and low-effort option to modify ones' cabin interior on the fly.

Both the concepts introduced above, consider furniture pieces that are commonly found in business jets. The applications are established while considering zero thickness for the furniture pieces, but these concepts can be expanded to account for a furniture piece's thickness by stacking each folded component's thickness in the final form. Unlike the Open-on-Demand application, the larger individual module size, unfavorable orientation, and combination make the furniture pieces in the Function family unviable candidates for the Reconfiguration application.

Certification is also an important aspect that needs to be considered during the implementation of the folding design concepts. Regulatory organizations have specific requirements for aircraft components and the folding concepts will need to address those requirements (FAA, 1964; TC, 2012) based on the purpose and application to be airworthy.

\section{Implementation Issues}

An actuation system is required to drive the folding process outlined in the folding methodology. The actuation system can be automated, electrically driven, or manual, human-driven. The manual process will entail the user unlocking the furniture piece's necessary joints, modifying the modules, and locking the new configuration. The automatic process will require an initiation input from the user, but the furniture pieces unlocking, modification, and relocking will be electrically powered. Micro-pin locks will be employed to secure the furniture piece's joints in place, and it can be manually engaged and disengaged using a push button.

Automated actuation while a non-intrusive process, adds more complexity to the furniture piece and hence increase the risk of failure along with increasing equipment cost and requiring frequent maintenance. Manual actuation is a simpler low-risk method of implementation but is a more physically involved process. A combination of the two actuation systems is a recommended method of implementation. The automated method provides a laid-back application of the concepts, and the manual method is a redundancy in case the automated method fails. 


\section{Simulation}

The advantage of the two folding applications introduced in this paper, Open-on-Demand and Reconfiguration, are illustrated through Figures 3-9. This is possible using a CAD simulation of the folding concepts in a simulated business jet cabin environment. The visual assessment highlights the advantages of the two concepts.

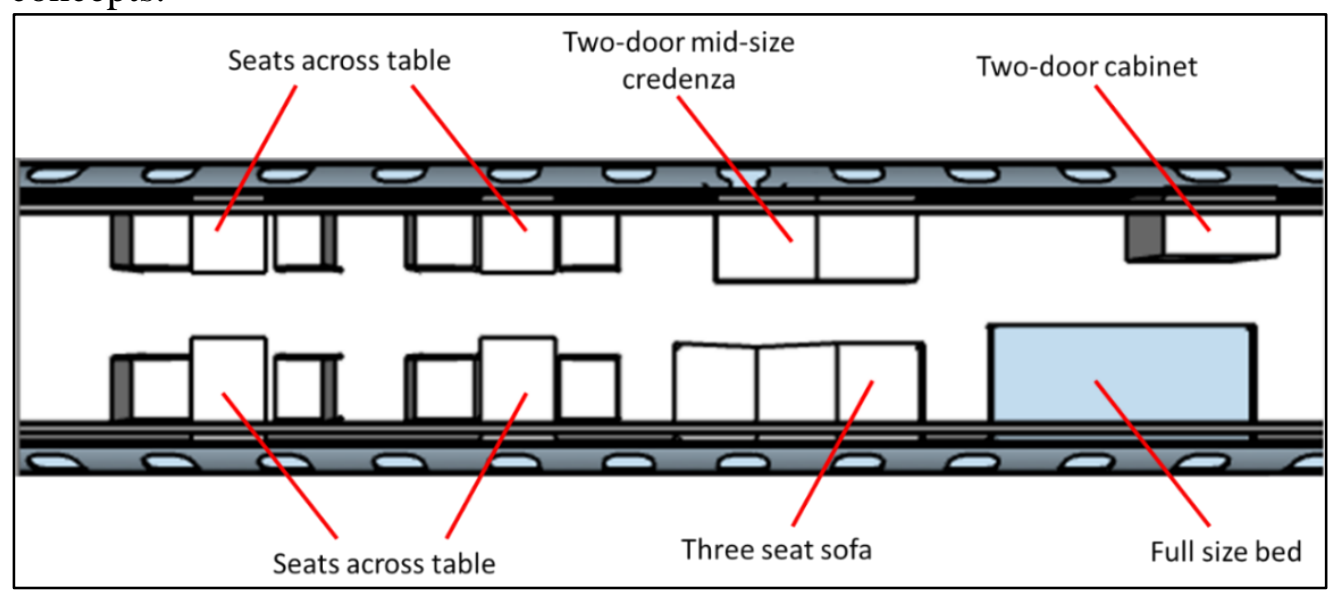

Figure 3. Partially sectioned top view with extended furniture pieces.

Figures 4 and Figure 5 illustrate the Open-on-Demand concept along the starboard and port sides of the partially sectioned cabin with zero-thickness furniture pieces. The area highlighted in yellow refers to the floor space the furniture pieces occupy in their extended forms.

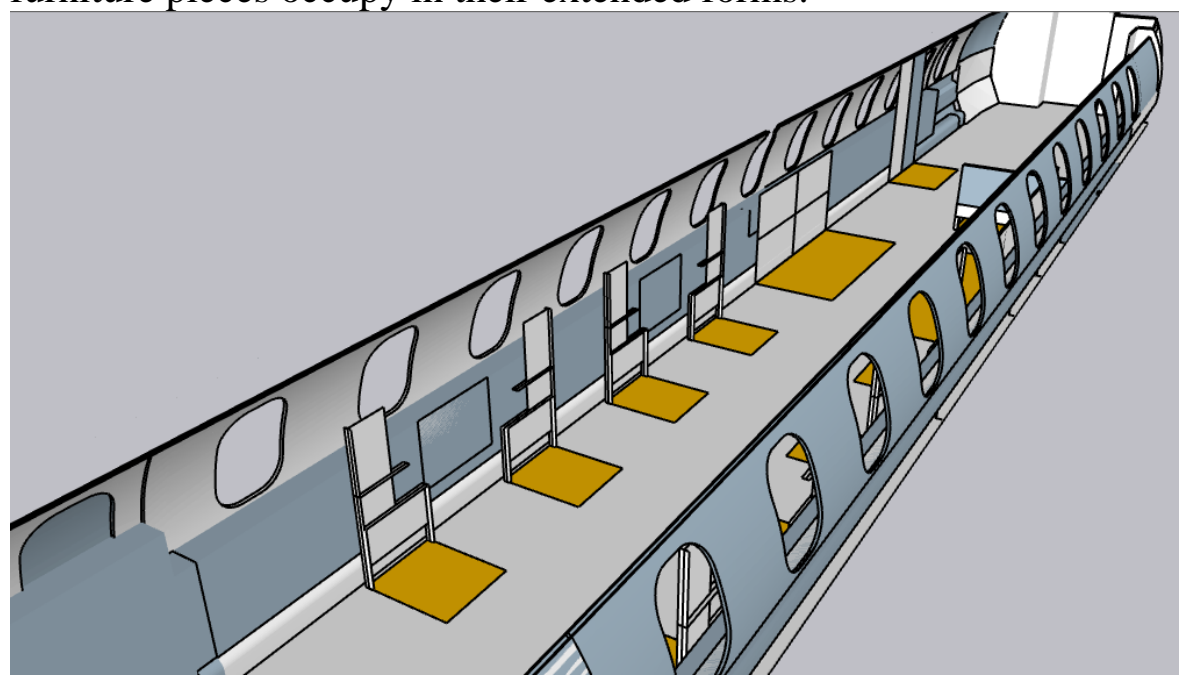

Figure 4. Starboard side partial section view with stowed furniture pieces. 


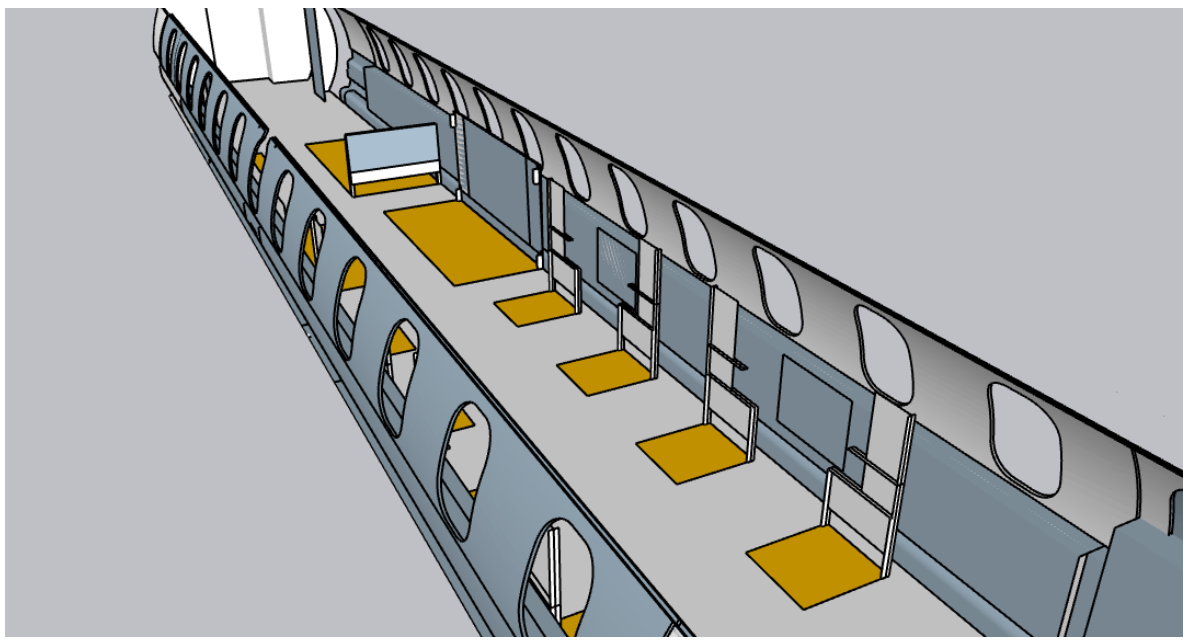

Figure 5. Port side partial section view with stowed furniture pieces.

Figure 6 depicts a partial section view of the port side of a business jet cabin with zero-thickness furniture pieces in their initial fully extended forms.

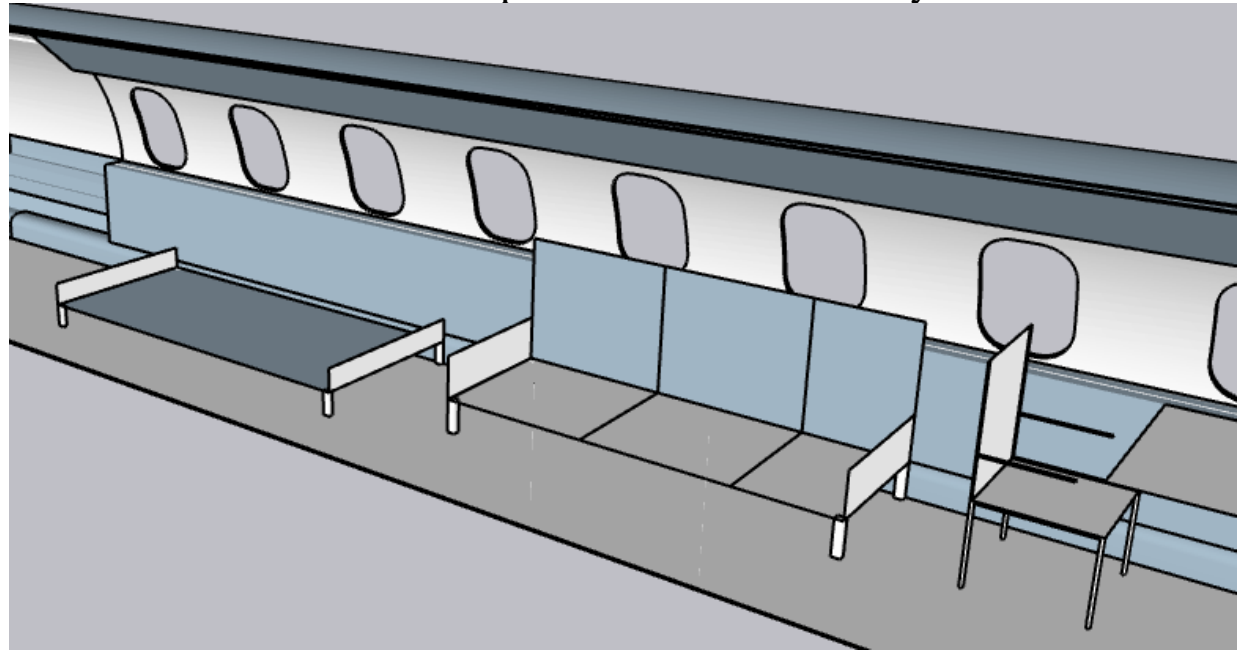

Figure 6. Port side partial section view of a business jet cabin.

Figures 7-9 illustrate the Reconfiguration concept applied to a zerothickness sofa and bed along the port side of the partially sectioned cabin. The area highlighted in yellow refers to the floor space the furniture pieces occupy in their initial forms. 
International Journal of Aviation, Aeronautics, and Aerospace, Vol. 8 [2021], Iss. 1, Art. 1

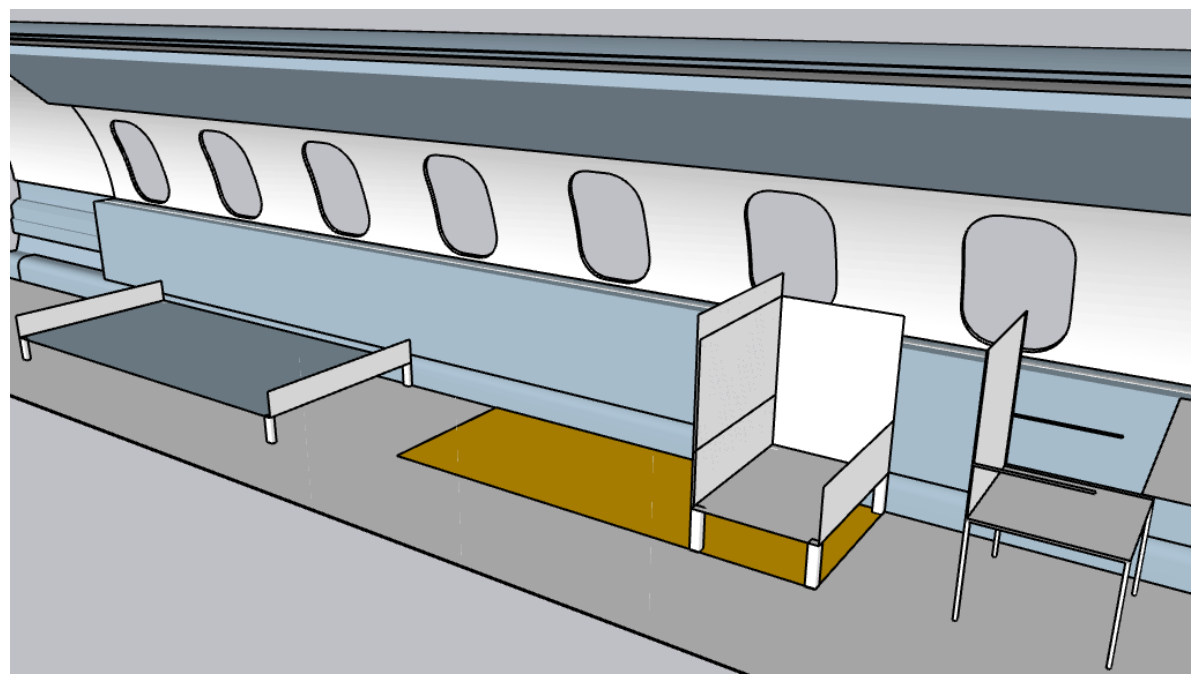

Figure 7. Port side partial section view of a sofa reconfigured into a seat.

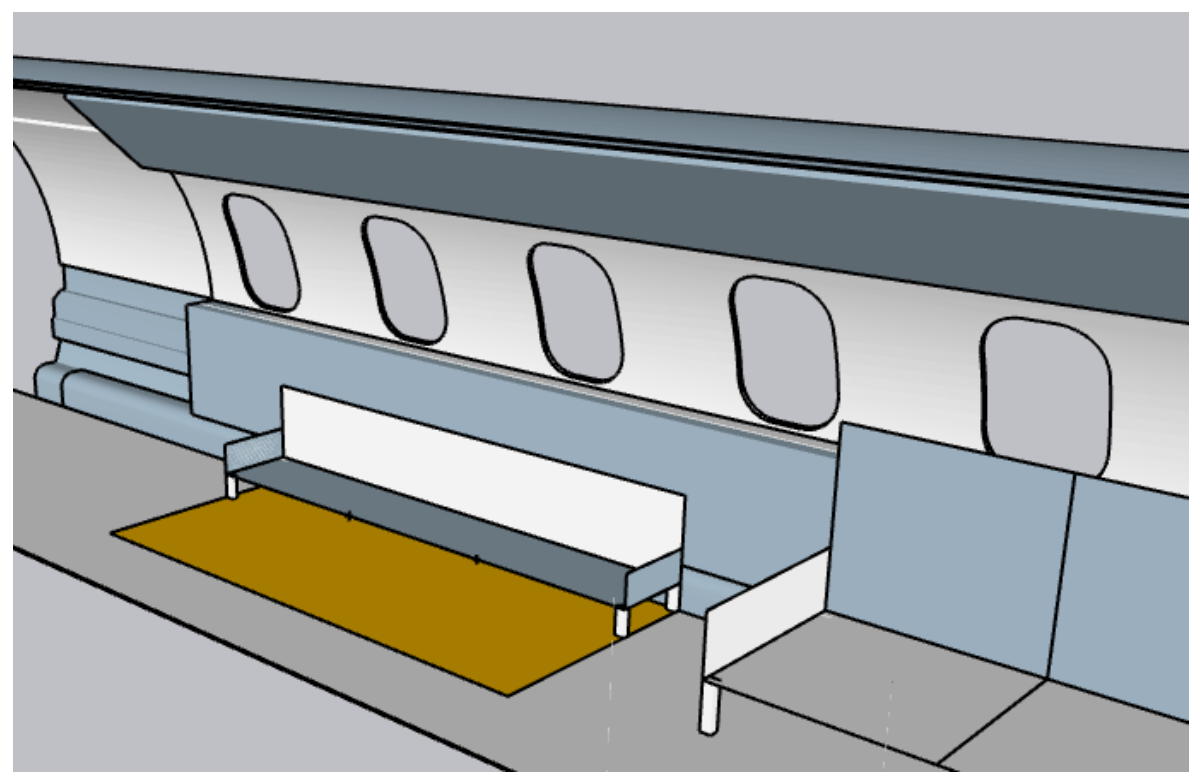

Figure 8. Port side partial section view of a bed reconfigured into a sofa. 


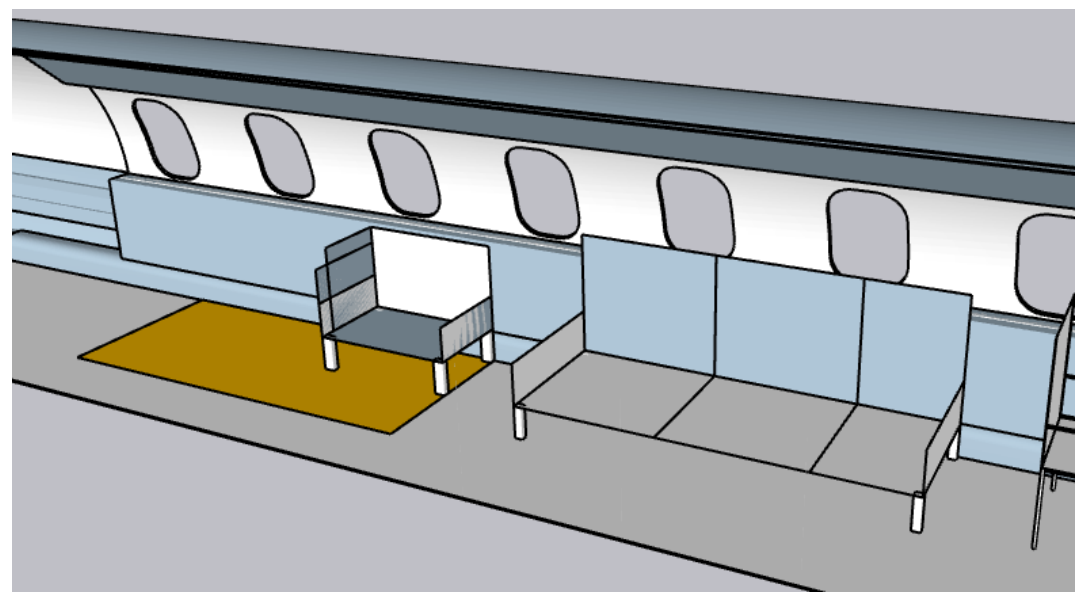

Figure 9. Port side partial section view of a bed reconfigured into a seat.

The furniture folding methodology can also be quantitively assessed to analyze advantages. A zero-thickness seat frame with measurements reflecting the lounge seat on a business jet was recreated using SketchUp 2020. Figure 10 illustrates an extended seat and stowed seat, following the furniture folding methodology, with a length of 27.25", width of 31.33 " and height of 44.23" and new a length of 2", width of 31.33 " and height of 44.23 ", respectively.
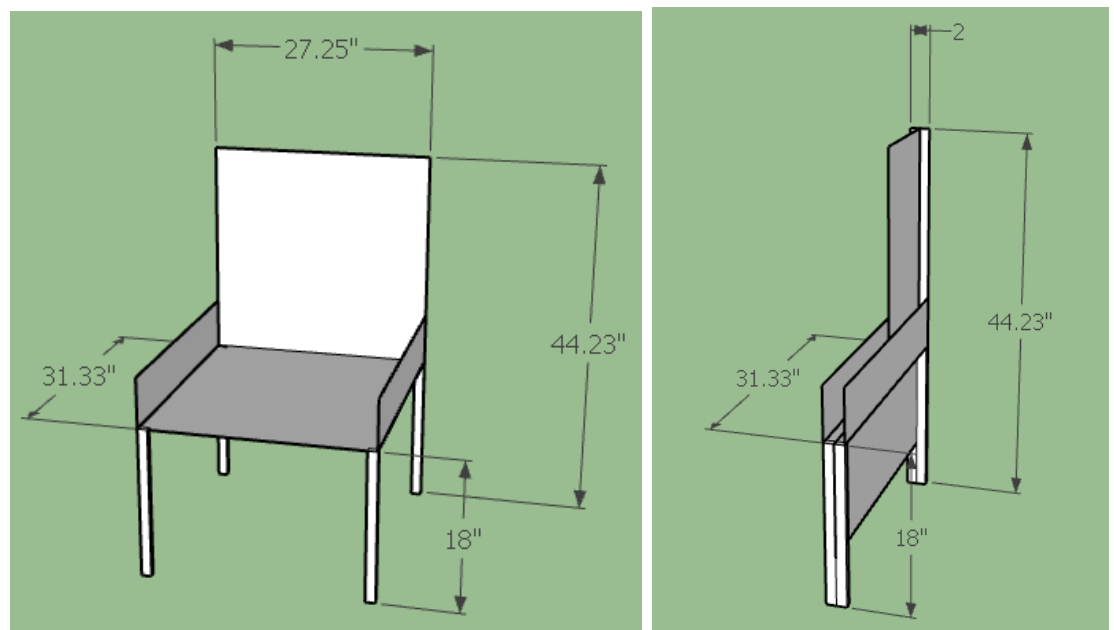

Figure 10. Recreation of an extended(left) and stowed(right) zero-thickness business jet lounge seat frame. 
The transformation of the extended seat to a stowed seat can be characterised using a FDM from Equation (2). The folding process modifies the DP of the extended seat to satisfy the FR of a stowed seat.

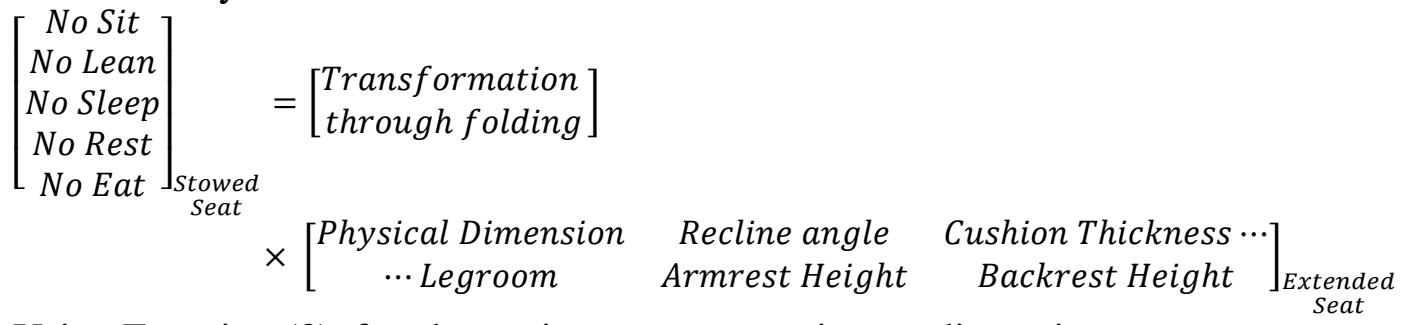

Using Equation (3), for change in measurement in one-dimension,

$$
\begin{gathered}
L_{1}=x L_{2} ; \\
27.25=x 2^{\prime \prime} ; \\
x=13.625
\end{gathered}
$$

The value of $x$ implies the seat has contracted by a factor of 13.625 in the length measurement.

Using the Entity Info tool in SketchUp 2020, the total surface area of the seat was determined to be $15.44 \mathrm{ft}^{2}$. The volume of the extended seat is $21.85 \mathrm{ft}^{3}$, while the volume of the stowed seat is $1.6 \mathrm{ft}^{3}$. Using Equation (4),

$$
\begin{gathered}
T C R=\text { Surface Area }(S A): \operatorname{Volume}(V) ; \\
T C R_{\text {extended }}=\frac{15.44 \mathrm{ft}^{2}}{21.85 \mathrm{ft}^{3}}=0.71 \mathrm{ft}^{-1} \\
T C R_{\text {stowed }}=\frac{15.44 \mathrm{ft}^{2}}{1.6 \mathrm{ft}^{3}}=9.65 \mathrm{ft}^{-1}
\end{gathered}
$$

The percentage change in denseness of the seat transformation can be calculated using Equation (5),

$$
\left(1-\frac{T C R_{\text {extended }}}{T C R_{\text {folded }}}\right) \times 100=\left(1-\frac{0.71}{9.65}\right) \times 100=92.64 \%
$$

This signifies the seat is $92.64 \%$ more compact when folded than in its extended form. While the above analysis is for an Open-on-Demand test case, the same approach can be followed for a Reconfiguration test case.

\section{Conclusion}

This paper outlines a framework to improve the on-board experience for passengers. The framework includes a design space decomposition which drives the general furniture folding methodology. The outcome of the framework can be quantitively analyzed using the methods introduced in this paper. The furniture folding methodology aims to minimize the footprint of furniture pieces while maximizing their functionality. Two design concepts, Open-on-Demand and Reconfiguration, were established as applications of the folding methodology. 
These applications increase the functionality of furniture pieces in a given space and allow the user to add a personal touch to an otherwise rigid environment.

While the initial simulation of the two design concepts does not consider the true thickness of the furniture pieces, future studies will include the analysis, simulation, and prototyping of all the furniture pieces at full-scale. Future studies will also consider certification standards for airworthiness and Human Factors (HF) for implementation to deliver a well-rounded product. While the proposed folding methodology applications are aimed at aircraft interiors, they can be expanded to consider any furniture piece in any given environment. 


\section{References}

Aircraft cabin interiors market by type (aircraft seating, IFEC, aircraft cabin lighting, aircraft galley, aircraft lavatory, aircraft windows \& windshields, aircraft interior panels), end user, aircraft type, material, region - global forecast to 2025. (2019, January). Retrieved May 04, 2020, from https://www.marketsandmarkets.com/ Market-Reports/aircraft-cabin-interiormarket-74760139.html

Annual Report of the Council - 2018. (2019). International Civil Aviation Organization (ICAO).

Bouwens, J. M., Tsay, W. J., \& Vink, P. (2017). The high and low comfort peaks in passengers' flight. Work, 58(4), 579-584. https://doi.org/10.3233/wor-172637

Cabin. (n.d.). Retrieved May 4, 2020, from https://www.tudelft.nl/en/ae/flying-v/cabin/

Davis, W., Frederick, C. M., \& Valois, K. K. (2003). Building a representation of aspect ratio. Journal of Vision, 3(12). http://doi.org/10.1167/3.12.13

Federal Aviation Administration. (1964). 14 CFR Part 25 airworthiness standards: Transport category airplanes. Retrieved From https://www.ecfr.gov/cgibin/retrieveECFR?gp=\&SID=bafc792f8722c29c2f52e7af95799b9b\&mc=true \&n $=$ t14.1.25\&r=PART\&ty=HTML

Federal Aviation Administration. (1972). 14 CFR Part 25.789 Retention of items of mass in passenger and crew compartments and galleys. Retrieved From https://www.ecfr.gov/cgi-bin/text-idx?node=14:1.0.1.3.11\#se14.1.25_1789

Hiemstra-van Mastrigt, S. (2015). Comfortable passenger seats: Recommendations for design and research. Delft University of Technology, Netherlands. https://doi.org/10.4233/uuid:eedd25e6-c625-45e9-9d32-f818aa89c19d

Johnson, M., Chen, Y., Hovet, S., Xu, S., Wood, B., Ren, H., Tokuda, J., \& Tse, Z. (2017). Fabricating biomedical origami: a state-of-the-art review. International Journal of Computer Assisted Radiology and Surgery, 12(11), 2023-2032. https://doi.org/10.1007/s11548-017-1545-1

Lang, R. J. (2009). Computational origami: From flapping birds to space telescopes. SCG '09. Association for Computing Machinery. https://doi.org/10.1145/1542362.1542363

Li, H., Hu, R., Alhashim, I., \& Zhang, H. (2015). Foldabilizing furniture. ACM Transactions on Graphics, 34(4), 1-12. https://doi.org/10.1145/2766912

Mollerup, P. (2001). Collapsible: The genius of space-saving design. San Francisco: Chronicle.

Reis, P. M., Jiménez, F. L., \& Marthelot, J. (2015). Transforming architectures inspired by origami. Proceedings of the National Academy of Sciences, 112(40), 1223412235. doi:10.1073/pnas.1516974112

Suh, N. P. (1995). Design and operation of large systems. Journal of Manufacturing Systems, 14(3), 203-213. https://doi.org/10.1016/0278-6125(95)98887-C

Suh, N. P. (1998). Axiomatic design theory for systems. Research in Engineering Design, 10(4), 189-209. doi:10.1007/s001639870001

Transport Canada. (1996). CAR SOR/96-433, Part VI: Subpart 2: Division IV: 602.86 Carry-on baggage, equipment and cargo. Retrieved From https://loislaws.justice.gc.ca/eng/regulations/SOR-96-433/FullText.html\#s-602.86 
Transport Canada. (2012). CAR SOR/96-433, Part V: Airworthiness manual chapter 525 - transport category aeroplanes. Retrieved From https://tc.canada.ca/en/ corporate-services/acts-regulations/list-regulations/canadian-aviation-regulationssor-96-433/standards/part-v-airworthiness-manual-chapter-525-transportcategory-aeroplanes-11

Turner, N., Goodwine, B., \& Sen, M. (2015). A review of origami applications in mechanical engineering. Proceedings of the Institution of Mechanical Engineers, Part C: Journal of Mechanical Engineering Science, 230(14), 2345-2362. https://doi.org/10.1177/0954406215597713

UKi Media \& Events. (2020, February 24). The 2020 crystal cabin awards finalists. Retrieved May 04, 2020, from https://www.aircraftinteriorsinternational.com/ features/the-2020-crystal-cabin-awards-finalists.html

Ultraflex. (2019, April 03). Retrieved May 04, 2020, from https://www.aimaltitude.com/ultraflex

Vink, P., Overbeeke, C., \& Desmet, P. (2004). Comfort experience. Comfort and Design, 1-12. https://doi.org/10.1201/9781420038132

Vink, P., Rotte, T., Anjani, S., Percuoco, C., \& Vos, R. (2020). Towards a hybrid comfortable passenger cabin interior for the flying $\mathrm{V}$ aircraft. International Journal of Aviation, Aeronautics, and Aerospace, 7(1). https://doi.org/10.15394/ijaaa.2020.1431 